\title{
Susceptibility to $\beta$-lactam agents of Yersinia enterocolitica biotype 4, serotype 03 isolated in various parts of the world
}

\author{
J. N. PHAM, S. M. BELL $\dagger$, M. J. HARDY, L. MARTIN*, A. GUIYOULE* and E. CARNIEL* \\ Department of Microbiology, The Prince of Wales Hospital, Randwick, NSW 2031, Australia and * Unité de \\ Bactériologie Moléculaire et Médicale, Institut Pasteur, 75724 Paris Cedex 15, France
}

\begin{abstract}
Summary. Forty-eight human isolates of Yersinia enterocolitica of biotype 4, serotype O3 from various parts of the world were examined for susceptibility to $13 \beta$-lactam agents. The intracellular $\beta$-lactamases of each of the 48 strains were examined. Isolates from Europe, Asia and Brazil (phage type VIII) or South Africa and Hungary (phage type IXa) produced both enzyme $A$ and enzyme $B$, whereas isolates from New Zealand and Australia (phage type IXb) lacked the cephalosporinase enzyme B. Among the seven strains isolated in Canada belonging to phage type IXb, three strains expressed only enzyme A (group I) whereas the other four strains produced both enzymes A and B (group II). The high susceptibility to the combination of amoxycillin and clavulanate observed in one subtype was explained by the absence of the cephalosporinase enzyme B. A simple disk diffusion test with this antibiotic combination was shown to be effective in the detection of enzyme B in $Y$. enterocolitica 4/O3.
\end{abstract}

\section{Introduction}

Yersinia enterocolitica biotype 4, serotype $\mathrm{O} 3$ (4/O3) has been reported worldwide as the predominant virulent bioserotype isolated from clinical specimens..$^{1-6}$ In a previous study of 100 clinical isolates of $Y$. enterocolitica from Australia, all $64 Y$. enterocolitica strains of biotype 4 were found to be highly susceptible to the combination of amoxycillin and clavulanate, unlike the isolates of biotypes $1 \mathrm{~A}$ and $3 .^{7}$ Furthermore, whilst $Y$. enterocolitica 4/O3 isolates from Europe were reported to produce two $\beta$-lactamases, enzymes $\mathrm{A}$ and $\mathrm{B},{ }^{8,9}$ all $64 Y$. enterocolitica $4 / \mathrm{O} 3$ isolates from Australia were found to express only the broad spectrum $\beta$-lactamase enzyme $A$ and lacked the cephalosporinase enzyme $B .^{10}$

In the present study, the susceptibility to $13 \beta$ lactam agents of 48 strains of $Y$. enterocolitica $4 / \mathrm{O} 3$ selected at random from isolates collected in various parts of the world, including Australia, was compared. Iso-electric focusing was also performed on crude enzyme preparations of each of the 48 strains and a simple agar disk diffusion test designed for the detection of enzyme B in $Y$. enterocolitica $4 / \mathrm{O} 3$ was also evaluated. $Y$. enterocolitica $4 / \mathrm{O} 3$ isolates from

Received 15 Sept. 1994; revised version accepted 12 Dec. 1994. $\uparrow$ Correspondence should be sent to Dr S. M. Bell.
Australia were shown previously to produce only one type of $\beta$-lactamase, enzyme A. ${ }^{10}$ However, as these strains were not included in the studies of Brenner et $a l .{ }^{11,12}$ in which DNA relatedness was used to characterise $Y$. enterocolitica sensu stricto, a DNA homology study was performed to establish homology between Australian and European isolates of $Y$. enterocolitica 4/O3.

\section{Materials and methods}

\section{Bacterial strains and culture conditions}

Forty-eight clinical isolates of $Y$. enterocolitica $4 / \mathrm{O} 3$ selected at random from those collected in various parts of the world were examined. Biotyping was performed as described previously ${ }^{7}$ and each strain, with the exception of four atypical isolates from Japan, was serotyped and phage typed at the Yersinia WHO Collaborating Centre, Institut Pasteur, Paris (table I). All cultures were incubated at $28^{\circ} \mathrm{C}$ in air throughout this study.

\section{Antibiotics and chemicals}

Amoxycillin, carbenicillin, clavulanic acid and ticarcillin (Beecham Research Laboratories), aztreonam (Squibb), cefoxitin and imipenem (Merck, Sharp and 
Table I. Phage type and country of origin of 48 strains of $Y$. enterocolitica biotype 4 , serotype $\mathrm{O} 3$ isolated in various parts of the world

Bio/serotype/phage type Number of strains Country of origin

\begin{tabular}{lll}
\hline 4/O3/VIII & 1 & Sweden \\
$4 / \mathrm{O} 3 /$ VIII & 4 & France \\
$4 / \mathrm{O} 3 /$ III & 5 & Japan \\
$4 / \mathrm{O} /$ VIII & 1 & China \\
$4 / \mathrm{O} 3 /$ VII & 5 & UK \\
$4 / \mathrm{O} 3 /$ VIII & 5 & Brazil \\
$4 * / \mathrm{O} 3 / \mathrm{VIII}$ & 4 & Japan \\
$4 / \mathrm{O} 3 / \mathrm{IXa}$ & 3 & South Africa \\
$4 / \mathrm{O} 3 / \mathrm{IXa}$ & 3 & Hungary \\
$4 / \mathrm{O} 3 / \mathrm{IXb}$ & 7 & Canada \\
$4 / \mathrm{O} 3 / \mathrm{IXb}$ & 5 & New Zealand \\
$4 / \mathrm{O} 3 / \mathrm{IXb}$ & 5 & Australia
\end{tabular}

* Atypical biotype 4/O3 isolated in Japan

Dohme), ceftazidime (Glaxo) cefotaxime (Roussel), cefotetan (Lederle) and ceftriaxone (Roche) were kindly supplied by the manufacturers or the agents. Ampicillin was purchased from Commonwealth Serum Laboratories, and nitrocefin (BR 63) and

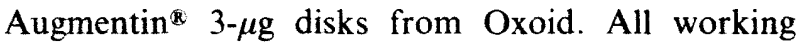
solutions were prepared freshly before use.

\section{DNA hybridisation}

DNA hybridisation was performed on three clinical isolates of $Y$. enterocolitica 4/O3-IP 21981 (4/O3/ VIII) isolated in France, IP 22273 and IP 22274 (4/O3/IXb) isolated in Australia--and also on the reference strain of $Y$. mollaretii IP 7263, formerly $Y$. enterocolitica biotype $3 \mathrm{~A} .{ }^{13}$ The latter strain was used as a control of a different species of Yersinia. The reference strain of $Y$. enterocolitica IP 134 (4/O3/VIII) was used as a source of labelled DNA according to the method described by Popoff and Coynault. ${ }^{14}$

\section{Determination of $M I C$}

The minimum inhibitory concentration (MIC) of 13 $\beta$-lactam agents was determined for all 48 isolates of $Y$. enterocolitica by an agar dilution technique as described previously. ${ }^{\top}$

\section{Determination of susceptibility by disk diffusion method}

A disk diffusion test with an Augmentin ${ }^{8}$ 3- $\mu \mathrm{g}$ (AMC 3) disk containing $2 \mu \mathrm{g}$ amoxycillin and $1 \mu \mathrm{g}$ clavulanic acid was performed on all 48 isolates according to the CDS method ${ }^{15}$ as described previously. ${ }^{16}$ The annular'radius of the zone of inhibition recorded with each strain was obtained by measuring the distance between the sharp edge of the confluent growth and the edge of the antibiotic disk. The mean of the results of three independent disk diffusion tests recorded with each strain was plotted against the MIC of amoxycillin in the presence of clavulanic acid $2 \mathrm{mg} / \mathrm{L}$.

\section{Assay of $\beta$-lactamase activity}

A crude enzyme extract of uninduced cultures of each of the 48 isolates of $Y$. enterocolitica was prepared and assayed for $\beta$-lactamase activity. In addition, each of the 48 isolates was induced with imipenem and the $\beta$-lactamase activity of induced cultures was assayed as described previously. ${ }^{17}$

\section{Iso-electric focusing of $\beta$-lactamases}

Iso-electric focusing on Ampholine PAG plates, $\mathrm{pH}$ range 3.5-9.5 (Linbrook International), was performed on each of the enzyme preparations from uninduced cultures and $\beta$-lactamase bands were visualised by overlaying the gels with a Whatman filter paper soaked in nitrocefin $1000 \mathrm{mg} / \mathrm{L}$, as described previously. ${ }^{10}$ Four pI markers were used: enzyme A with a $\mathrm{pI}$ of 8.7 and enzyme B with pIs of 5.3 and 5.7 were from the reference strain of $Y$. enterocolitica IP 134 (4/O3/VIII) which produced both enzymes A and B, a TEM $\beta$-lactamase from Haemophilus influenzae with a $\mathrm{pI}$ of $5 \cdot 4$, and a chromosomal cephalosporinase with a pI of 7.4 from Enterobacter cloacae ATCC 13047.

\section{Results}

\section{Biotyping, serotyping and phage typing}

All 48 isolates of $Y$. enterocolitica $4 / \mathrm{O} 3$ showed typical biochemical reactions of biotype 4 described in the revised biogrouping scheme for $Y$. enterocolitica. ${ }^{18}$ However, the four atypical isolates from Japan showed some unusual biochemical reactions. Strains Pa 3171 and $\mathrm{Pa} 4918$ failed to decarboxylate ornithine and strains $\mathrm{Pa} 1128$ and $\mathrm{Pa} 2839$ failed to ferment maltose although they produced $\alpha$-glucosidase. These atypical strains were proposed by Fukushima et al. ${ }^{19}$ as belonging to biotypes $4 \mathrm{~A}$ and $4 \mathrm{~B}$, respectively. All 48 isolates were found to belong to serotype O3. Twentyfive isolates belonged to phage type VIII, six to phage type IXa and 17 to phage type IXb.

\section{DNA hybridisation}

There was a high degree of homology between the three strains of biotype 4 tested and the reference strain of $Y$. enterocolitica IP 134 (4/O3/VIII) used as the source of labelled DNA. The degrees of relatedness at $65^{\circ} \mathrm{C}$ were, respectively, $88 \%, 100 \%, 92.9 \%$ and $47 \cdot 4 \%$ for strains IP 21981 (4/O3/VIII), IP 22273 (4/O3/IXb), IP 22274 (4/O3/IXb) and the reference strain of $Y$. mollaretii IP 7263 , formerly $Y$. enterocolitica biotype $3 \mathrm{~A} .^{13}$

\section{Determination of $M I C$}

All 48 strains of $Y$. enterocolitica 4/O3 were resistant to ampicillin, carbenicillin and ticarcillin. The ranges of MIC in $\mathrm{mg} / \mathrm{L}$ were $32-64$ for ampicillin, 256-512 
Table II. Susceptibility of $Y$. enterocolitica $4 / \mathrm{O} 3$ to three selected $\beta$-lactam agents and the $\beta$-lactamases produced by strains within each subgroup

\begin{tabular}{lcccc}
\hline \multirow{2}{*}{$\begin{array}{l}\text { Biotype } \\
\text { (number of strains) }\end{array}$} & \multicolumn{2}{c}{ MIC range (mg/L) of } & $\beta$-Lactamase \\
\cline { 2 - 4 } & amoxycillin & amox/clav* & cefoxitin & \\
\hline 4/O3/IXb/Can/I (3) & $64-128$ & $0 \cdot 5$ & $1-2$ & $\mathrm{~A}$ \\
4/O3/IXb/NZ (5) & $64-128$ & $0 \cdot 5$ & $1-2$ & $\mathrm{~A}$ \\
4/O3/IXb/Aus (5) & $64-128$ & $0 \cdot 5$ & $1-2$ & $\mathrm{~A}$ \\
4/O3/VIII (25) & $64-128$ & $8-16$ & $4-8$ & $\mathrm{~A}+\mathrm{B}$ \\
4/O3/IXa (6) & $64-128$ & 16 & $4-8$ & $\mathrm{~A}+\mathrm{B}$ \\
4/O3/IXb/Can/II (4) & $128-256$ & 32 & $16-32$ & $\mathrm{~A}+\mathrm{B}$ \\
\hline
\end{tabular}

* Amoxycillin in the presence of clavulanate $2 \mathrm{mg} / \mathrm{L}$.
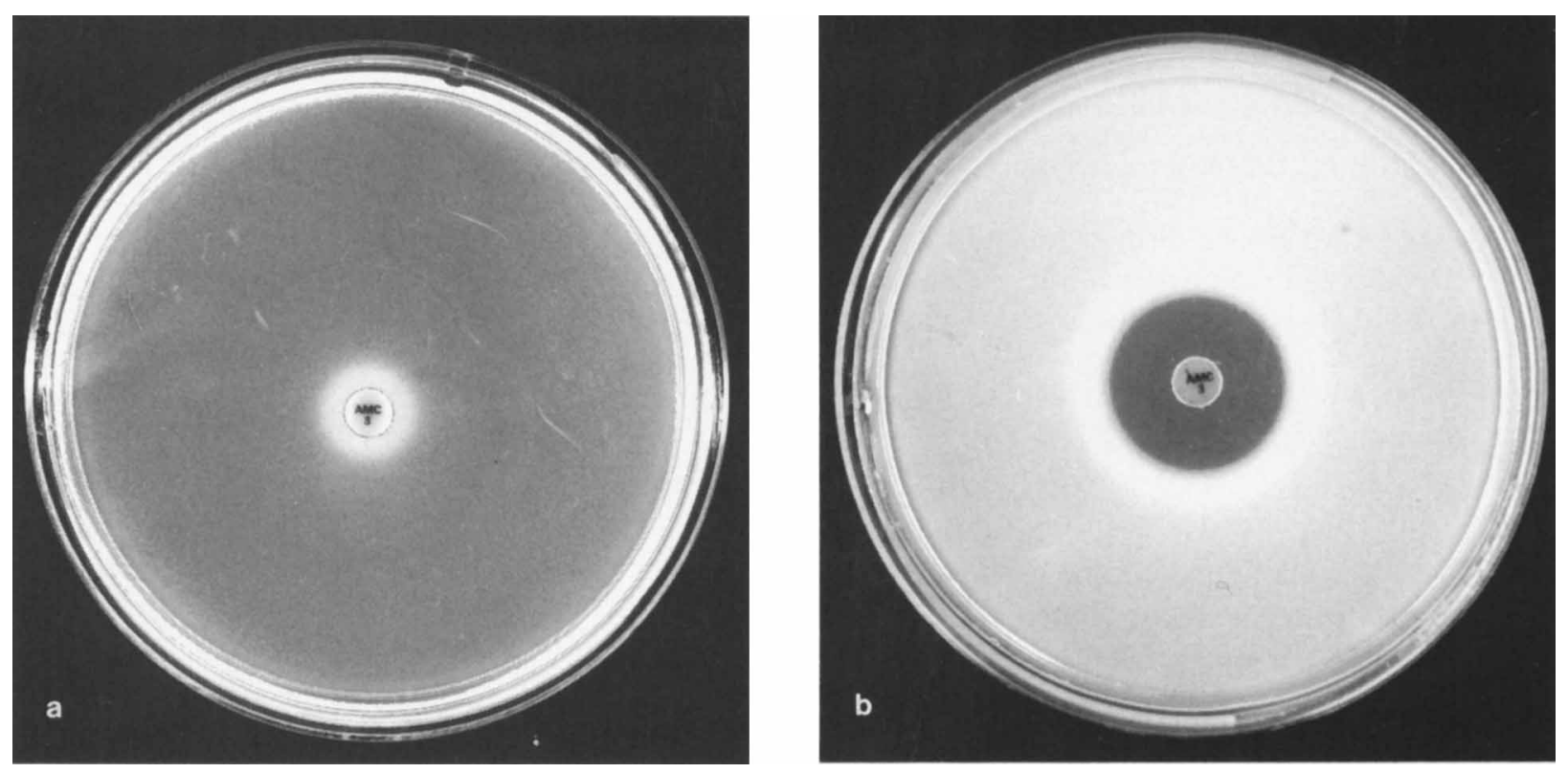

Fig. 1. A strain of $Y$. enterocolitica $(4 / \mathrm{O} 3 / \mathrm{IXb} / \mathrm{Can} / \mathrm{II})$ showing no zone of inhibition (a) and a strain of $Y$. enterocolitica $(4 / \mathrm{O} 3 / \mathrm{IXb} / \mathrm{Can} / \mathrm{I})$ showing a zone of inhibition with an annular radius of $7.5 \mathrm{~mm}$ (b) with an Augmentin ${ }^{\circledR} 3-\mu \mathrm{g}$ (AMC3) disk in the CDS disk diffusion test.

for carbenicillin and 128-256 for ticarcillin. By contrast, all 48 strains showed uniform susceptibility in vitro to newer $\beta$-lactam agents (range of MIC in $\mathrm{mg} / \mathrm{L}$ of each antibiotic shown in parenthesis after each agent): aztreonam $(0 \cdot 5-1 \cdot 0)$, ceftazidime $(0.03-0.06)$, cefotaxime $(0.03-0 \cdot 06)$, cefotetan $(0 \cdot 12-0 \cdot 25)$ ceftriaxone $(0.03-0.06)$, imipenem $(0.25)$ and to the combination of ticarcillin and clavulanate (Timentin ${ }^{\circledR}$, 1-4). The MIC values or the ranges of MIC in $\mathrm{mg} / \mathrm{L}$ for strains within each subtype of amoxycillin, amoxycillin and clavulanate and cefoxitin are shown in table II. The 10 strains isolated in New Zealand and Australia $(4 / \mathrm{O} 3 / \mathrm{IXb})$ and three of seven strains isolated in Canada (IP 4119, IP 4124 and IP 4126) showed an exceptionally high susceptibility to the combination of amoxycillin and clavulanate (Augmentin $^{\mathbb{Q}}$ ) with an MIC of amoxycillin of 0.5 $\mathrm{mg} / \mathrm{L}$ in the presence of clavulanic acid $2 \mathrm{mg} / \mathrm{L}$. The group of Canadian $Y$. enterocolitica 4/O3/IXb strains highly susceptible to amoxycillin plus clavulanate was designated group I Canadian 4/O3 (4/O3/IXb/ $\mathrm{Can} / \mathrm{I})$. Strains from Europe, Asia and Brazil (4/O3/ VIII), South Africa and Hungary (4/O3/IXa) and the remaining four Canadian strains (IP 4115, IP 4122, IP 4123 and IP 4125) had MIC values of amoxycillin ranging from 8 to $32 \mathrm{mg} / \mathrm{L}$ in the presence of clavulanic acid $2 \mathrm{mg} / \mathrm{L}$. This group of Canadian 4/O3, resistant to amoxycillin and clavulanate, was referred to as group II Canadian 4/O3 (4/O3/IXb/Can/II).

\section{Determination of susceptibility by the disk diffusion method}

Y. enterocolitica 4/O3 strains from Europe, Asia and Brazil (4/O3/VIII), South Africa and Hungary (4/O3/IXa) and group II Canadian 4/O3 strains showed either no zone of inhibition (fig. 1a) or a zone of inhibition with an annular radius $\leqslant 3 \mathrm{~mm}$ with an Augmentin ${ }^{\circledR} 3-\mu \mathrm{g}$ disk. All 10 strains isolated in New Zealand and Australia and the three strains of group I Canadian 4/O3 gave a zone of inhibition with an annular radius greater than the 6 -mm cut-off value for the method with zone sizes ranging from 6.8 to $7.5 \mathrm{~mm}$ with an Augmentin ${ }^{\circledR} 3-\mu$ g disk (fig. 1b). A definite bimodal distribution was obtained when measurements of the annular radius of the zones of inhibition 


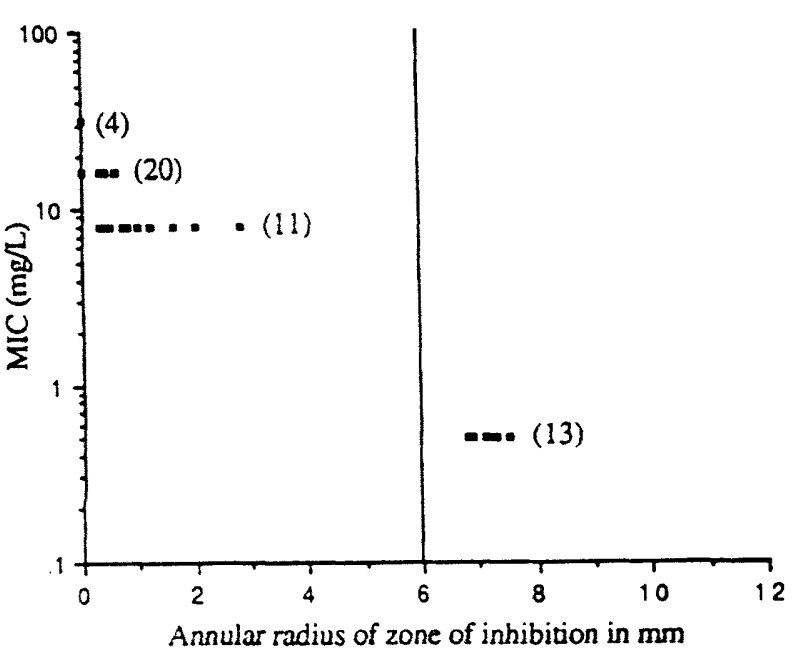

Fig. 2. Graph shows MIC values of amoxycillin in the presence of clavulanic acid $2 \mathrm{mg} / \mathrm{L}$ versus annular radius of zone of inhibition obtained by the CDS disk diffusion method with an Augmentin 3- $\mu \mathrm{g}$ (AMC3) disk with 48 strains of $Y$. enterocolitica 4/O3. The numbers of isolates at each MIC value are shown in brackets.

around Augmentin $3-\mu \mathrm{g}$ disks of the $48 Y$. enterocolitica isolates were plotted against the respective MIC values of the combination of amoxycillin and clavulanate (fig. 2).

\section{$\beta$-Lactamase activity}

All 48 strains of $Y$. enterocolitica were found to produce $\beta$-lactamase when nitrocefin was used as substrate to test the crude enzyme extracts. The $\beta$ lactamase activity of uninduced cultures of the $10 \mathrm{New}$ Zealand and Australian isolates and the three Canadian isolates of group I ranged from 0.07 to $0 \cdot 10$ $\mu \mathrm{mol}$ nitrocefin hydrolysed $/ \mathrm{min} / \mathrm{mg}$ of protein. The activity of the remaining 35 isolates ranged from $0 \cdot 11$ to $0.37 \mu \mathrm{mol}$ nitrocefin hydrolysed $/ \mathrm{min} / \mathrm{mg}$ of protein. After exposure to imipenem, $\beta$-lactamase activity of the first group was unaltered whereas the activity of the second group was enhanced and ranged from 0.46 to $6.93 \mu \mathrm{mol}$ nitrocefin hydrolysed $/ \mathrm{min} / \mathrm{mg}$ of protein.

\section{Iso-electric focusing}

Ten strains from New Zealand and Australia and three strains of group I Canadian 4/O3 gave a single band of $\beta$-lactamase with a $\mathrm{pI}$ of 8.7 corresponding to enzyme A. Enzyme preparations of strains from Europe, Asia and Brazil (4/O3/VIII), Hungary and South Africa (4/O3/IXa) and of group II Canadian $4 / \mathrm{O} 3$ strains gave two groups of $\beta$-lactamase bands-a single band with a pI of 8.7 corresponding to enzyme $A$ and a double band with pIs of 5.3 and 5.7 corresponding to enzyme $\mathrm{B}$, described by Cornelis and Abraham. ${ }^{8}$ Table II shows the cumulative results of the type of $\beta$-lactamase produced by strains within each group.

\section{Discussion}

All 48 strains of $Y$. enterocolitica $4 / \mathrm{O} 3$ were found to be uniformly susceptible to the six newer $\beta$-lactam agents-aztreonam, ceftazidime, cefotaxime, cefotetan, ceftriaxone, imipenem and to the combination ticarcillin and clavulanate. These results agreed with findings reported in studies conducted in Europe on in-vitro susceptibilities to $\beta$-lactam antibiotics of clinical isolates of $Y$. enterocolitica. ${ }^{20,21}$ All of the $10 \mathrm{New}$ Zealand and Australian isolates and the three Canadian isolates of group I were resistant to amoxycillin but were susceptible to amoxycillin plus clavulanate and cefoxitin. On iso-electric focusing, each isolate gave a single $\beta$-lactamase band with a $\mathrm{pI}$ of 8.7 and none showed any increase in $\beta$-lactamase activity in the presence of imipenem. In previous studies, it was established that all of these characteristics correlated with the production of the non-inducible broad spectrum $\beta$-lactamase enzyme A. ${ }^{7,10,16,17}$ The remaining 35 isolates had a similar level of resistance to amoxycillin as the other 13 isolates, were resistant to amoxycillin plus clavulanate and cefoxitin and gave two groups of $\beta$-lactamases with $\mathrm{pIs}$ of $5 \cdot 3-5 \cdot 7$ and $8 \cdot 7$. The $\beta$ lactamase activity of each isolate of this group was enhanced when imipenem was used as inducer. It was also shown previously that these characteristics were unique to those strains possessing both the broad spectrum enzyme $\mathrm{A}$ and the cephalosporinase enzyme B of Cornelis and Abraham. ${ }^{8}$

In DNA hybridisation with probes prepared from strain IP 134, a reference strain of $Y$. enterocolitica $4 / \mathrm{O} 3$, the high degree of DNA homology of $92.9 \%$ and $100 \%$ obtained with the two Australian 4/O3 strains confirmed that $Y$. enterocolitica $4 / \mathrm{O} 3$ isolates from Australia belong to the species $Y$. enterocolitica, even though they produce only enzyme $A$ and lacked enzyme B. Furthermore, three of seven strains of $Y$. enterocolitica 4/O3 isolated in Canada and all five strains isolated in New Zealand were also found in the present study to lack enzyme B and were, therefore, identical to Australian 4/O3 strains in the expression of $\beta$-lactamase.

Phage-typing results performed in the present study on the 48 strains of $Y$. enterocolitica $4 / \mathrm{O} 3$ isolated in various parts of the world revealed that phage type VIII was the most common phage type of $Y$. enterocolitica 4/O3 worldwide. Strains from Asia, South America and Europe, with the exception of Hungary, belonged to phage type VIII. All three strains of $Y$. enterocolitica 4/O3 from Hungary were found to belong to phage type IXa, the "South African phage type". The observation that all 10 strains of $Y$. enterocolitica 4/O3 isolated in New Zealand and Australia belonged to the less common phage type $\mathrm{IXb}$, the "Canadian phage type", was of great interest. The information that these two neighbouring countries shared the same phage type once more confirmed that the phage type in $Y$. enterocolitica is an indicator of the geographic origin as first described in 1976 by Nicole et al. ${ }^{22}$

Strains of phage types VIII and IXa isolated in different parts of the world appeared to be uniform in 
the expression of $\beta$-lactamase which resulted in their similar patterns of susceptibility to $\beta$-lactam antibiotics. In the present study, all 25 strains of $4 / \mathrm{O} 3 / \mathrm{VIII}$, including the four biochemically atypical strains isolated in Japan $(4 * / \mathrm{O} 3 / \mathrm{VIII})$, and all six strains 4/O3/IXa were found to produce both enzymes $\mathrm{A}$ and $\mathrm{B}$ on iso-electric focusing. This finding confirmed earlier observations by Matthew et al. ${ }^{23}$ on the production of two types of $\beta$-lactamases by $Y$. enterocolitica 4/O3 strains isolated in Europe. $Y$. enterocolitica $4 / \mathrm{O} 3 / \mathrm{IXb}$ isolates in Canada, Australia and New Zealand, unlike strains of phage type VIII and IXa, produced either both enzymes A and B or enzyme A alone. All 10 strains of $4 / \mathrm{O} 3 / \mathrm{IXb}$ from Australia and New Zealand were found to lack enzyme $B$ whereas only three of seven strains from Canada lacked this enzyme.

The CDS agar disk diffusion susceptibility test with an Augmentin ${ }^{\circledR} 3-\mu \mathrm{g}$ disk was found to be a simple yet very reliable method for detecting the presence of enzyme B in $Y$. enterocolitica $4 / \mathrm{O} 3$. Strains expressing

\section{References}

1. Mollaret $\mathbf{H H}$, Bercovier H, Alonso JM. Summary of the data received at the WHO Reference Center of Yersinia enterocolitica. Contrib Microbiol Immunol 1979; 5: 174-184.

2. Toma S, Lafleur L. Yersinia enterocolitica infections in Canada 1966 to August 1978. In: Bottone EJ (ed) Yersinia enterocolitica. Florida, CRC Press. 1981: 183-191.

3. Robins-Browne RM, Rabson AR, Koornhof HJ. Yersinia enterocolitica in South Africa. In: Bottone EJ (ed) Yersinia enterocolitica Florida, CRC Press. 1981: 193-203.

4. Mingrone MG, Fantasia M, Figura N, Guglielmetti P. Characteristics of Yersinia enterocolitica isolated from children with diarrhea in Italy. $J$ Bacteriol 1987 ; 25: 1301-1304.

5. Marriott D. Yersinia enterocolitica infection in children in New South Wales. Contrib Microbiol Immunol 1987; 9: 98-102.

6. Bottone EJ, Gullans CR, Sierra MF. Disease spectrum of Yersinia enterocolitica serogroup $\mathrm{O}: 3$, the predominant cause of human infection in New York City. Contrib Microbiol Immunol 1987; 9: 56-60.

7. Pham JN, Bell SM, Lanzarone JYM. Biotype and antibiotic sensitivity of 100 clinical isolates of Yersinia enterocolitica. $J$ Antimicrob Chemother $1991 ; 28$ : 13-18.

8. Cornelis G, Abraham EP. $\beta$-Lactamases from Yersinia enterocolitica. J Gen Microbiol 1975; 87: 273-284.

9. Cornelis G. Distribution of $\beta$-lactamases $A$ and $B$ in some groups of Yersinia enterocolitica and their role in resistance. $J$ Gen Microbiol 1975; 91 : 391-402.

10. Pham JN, Bell SM, Lanzarone JYM. A study of the $\beta$ lactamases of 100 clinical isolates of Yersinia enterocolitica. $J$ Antimicrob Chemother 1991; 28: 19-24.

11. Brenner DJ, Steigerwalt AG, Falcao DP, Weaver RE, Fanning GR. Characterisation of Yersinia enterocolitica and Yersinia pseudotuberculosis by deoxyribonucleic acid hybridization and by biochemical reactions. Int $J$ Syst Bacteriol 1976; 26: 180-194.

12. Brenner DJ, Ursing J, Bercovier $\mathrm{H}$ et al. Deoxyribonucleic acid relatedness in Yersinia enterocolitica and Yersinia enterocolitica-like organisms. Curr Microbiol 1980; 4: 195-200. the cephalosporinase enzyme B were found to show a zone of inhibition with an annular radius $\leqslant 3 \mathrm{~mm}$. The presence of clavulanate in the disk not only failed to inhibit enzyme B but acted as an inducer of cephalosporinase, conferring resistance to the antibiotic combination. Such strains were easily distinguished from strains which, due to the absence of enzyme B, showed a zone of inhibition with an annular radius $\geqslant 6 \mathrm{~mm}$. This simple enzyme $\mathrm{B}$ detection test would be most useful in the differentiation between group I and group II $Y$. enterocolitica $4 / \mathrm{O} 3$ isolates from Canada, a country where the differentiation would be valuable both epidemiologically and clinically, given the high susceptibility of group I strains to cefoxitin and amoxycillin plus clavulanate. Furthermore, the test would enable the screening of a large number of isolates of the three phage types VIII, IXa and IXb from different countries confirming the distribution of the two $\beta$-lactamases that was observed with the relatively small sample of isolates examined in the present study.

13. Wauters G, Janssens M, Steigerwalt AG, Brenner DJ. Yersinia mollaretii sp. nov. and Yersinia bercovieri sp. nov., formerly called Yersinia enterocolitica biogroups $3 \mathrm{~A}$ and 3B. Int $J$ Syst Bacteriol 1988; 38: 424-429.

14. Popoff $M$, Coynault C. Use of DEAE-cellulose filters in the $S 1$ nuclease method for bacterial deoxyribonucleic acid hybridization. Ann Microbiol 1980; 131A: 151-155.

15. Bell SM. The CDS disc method of antibiotic sensitivity testing (calibrated dichotomous sensitivity test). Pathology 1975; 7: 1-48 (supplement).

16. Pham JN, Bell SM. The detection by a disc diffusion technique of inducible $\beta$-lactamase in Yersinia enterocolitica. $J$ Antimicrob Chemother 1993; 31: 1004-1005.

17. Pham JN, Bell SM. The prevalence of inducible $\beta$-lactamase in clinical isolates of Yersinia enterocolitica. Pathology 1993; 25: $385-387$.

18. Wauters G, Kandolo K, Janssens M. Revised biogrouping scheme of Yersinia enterocolitica. Contrib Microbiol Immunol 1987; 9: 14-21.

19. Fukushima H, Tsubokura M, Otsuki K, Kawaoka Y. Biochemical heterogeneity of serotype $0: 3$ strains of 700 Yersinia strains isolated from humans, other mammals, flies, animal feed and river water. Curr Microbiol 1984; 11: 149-154.

20. Hornstein MJ, Jupeau AM, Scavizzi MR, Philippon AM, Grimont PA. In vitro susceptibilities of 126 clinical isolates of Yersinia enterocolitica to $21 \beta$-lactam antibiotics. Antimicrob Agents Chemother 1985; $27: 806-811$.

21. Gahrn-Hansen B, Sogaard P. In-vitro activity of cefotaxime against clinical isolates of Yersinia enterocolitica, biotype 4, serotype O:3. J Antimicrob Chemother 1990; 26: 599-601.

22. Nicolle P, Mollaret $\mathrm{HH}$, Brault J. La lysotypie de Yersinia enterocolitica. Arguments géographiques, zoologiques, antigéniques et biochimiques plaidant en sa faveur. Bull Acad Natl Med 1976; 160: 404-408.

23. Matthew M, Cornelis G, Wauters G. Correlation of serological and biochemical groupings of Yersinia enterocolitica with the $\beta$-lactamases of the strains. $J$ Gen Microbiol 1977; 102: 55-59. 